\title{
COMPLEMENTARIDADE ENTRE CAMPO E LABORATÓRIO COMO RECURSO DIDÁTICO NA GEOGRAFIA: EXPERIÊNCIA A PARTIR DE UM MAPEAMENTO PEDOLÓGICO
}

\author{
Jocasta Fernandes Magalhães ${ }^{(a)}$, Danilo Mangaba de Camargo $^{(\mathrm{b})}$, Estéfano Seneme Gobbi ${ }^{(\mathrm{c})}$
}

(a) Pontifícia Universidade Católica de Campinas, E-mail: jocastafernandes2014@ gmail.com

(b) Programa de Pós-Graduação em Geociências e Meio Ambiente, Universidade Estadual Paulista Júlio de Mesquita Filho, E-mail: danilo.mangaba@gmail.com;

${ }^{(c)}$ Universidade Estadual de Campinas, E-mail: estefano.gobbi@puc-campinas.edu.br

\section{EIXO: GEOGRAFIA FÍSICA - CURRÍCULO, FORMAÇÃO E PRÁTICAS DE ENSINO}

\section{Resumo}

\begin{abstract}
Campo e gabinete são etapas complementares e intrínsecas ao trabalho do geógrafo de modo que, na formulação do conhecimento sobre as relações entre os diversos componentes da paisagem, essas etapas devem ser vivenciadas desde os primeiros anos de sua formação na graduação. Dentro desse contexto o presente trabalho objetiva uma reflexão acerca das atividades externas e de laboratório na formação do geógrafo. Para tanto o artigo apresenta uma sucinta revisão sobre a importância do trabalho de campo na Geografia brasileira seguido de um relato de experiência a partir de um exercício de mapeamento pedológico em uma área do município de Morungaba, SP. Observou-se que tais recursos didáticos atuam diretamente no treinamento de exercícios que são atribuídos ao Geógrafo no mercado de trabalho, bem como, a importância do mapeamento de detalhe como fonte para estudos e pesquisas ambientais.
\end{abstract}

Palavras chave: Solos; Paisagem; Mapeamento pedológico; Ensino de Geografia

\section{Introdução}

$\mathrm{Na}$ formulação do conhecimento geográfico sobre o mundo, o trabalho de campo e o de gabinete tornamse etapas complementares para se adquirir a expertise necessária para sua efetivação. Com efeito, o trabalho de campo só faz sentido se redundar em novos conhecimentos que, para alçarem a alcunha científica, devem ser devidamente sistematizados, levando em conta que essa sistematização é obtida justamente no gabinete.

O trabalho de Campo é tido como um momento privilegiado para aprendizagem e aplicação de conceitos geográficos, pois, "permite uma aproximação da teoria e da prática, ampliando a capacidade de observar, documentar, aprender e problematizar" (CAMPOS; PLACIDO, 2011, p. 07). Entende-se que o campo é o grande agente integrador capaz de superar ou ao menos mitigar os danos causados pelo saber fragmentado. É também na observação da realidade que a curiosidade é aguçada, onde os sentidos e o intelecto são provocados e aonde os indivíduos vêm-se diante do dever moral de propor explicações e soluções diante dos fenômenos observados. Cantão (1956, p. 503), afirma que "o aluno que apenas estuda 
pelo livro ou por notas de aula, fica confuso diante de uma paisagem. Não correlaciona o estudado em classe com o panorama que se abre diante dele".

Já no que tange ao trabalho de gabinete, a atenção é voltada para procedimentos e técnicas, muitas vezes relacionadas à particularidade do objeto estudado (VENTURI, 2005). É no gabinete (laboratório em alguns casos), por exemplo, que etapas importantes de uma pesquisa como a revisão bibliográfica e a elaboração de mapeamentos são levadas a cabo.

Vale salientar, contudo, que nem sempre a complementariedade entre essas duas etapas de trabalho estiveram evidenciadas, de maneira que durante os diversos períodos da história da Geografia brasileira, ênfase foi dada a uma ou outra perspectiva. Guimarães (1999), através de uma pesquisa bibliográfica, traça um panorama de como fora pensado o trabalho de campo ao longo dos períodos históricos e seus respectivos paradigmas na Geografia nacional. De modo geral observa-se que os trabalhos de campo foram muito difundidos no período Tradicional da Geografia, mais ou menos relegados durante o período da Nova Geografia (teorética), que deu ênfase a modelagem de dados e ao trabalho laboratorial. Diante disso, vê-se que essa estratégia de ensino-aprendizagem adquire novo fôlego diante dos novos paradigmas, sobretudo a análise sistêmica dos componentes da paisagem.

A união campo-laboratório contribui significativamente para processo de ensino aprendizagem, instigando o aluno a olhar de forma mais crítica para a realidade que o cerca, e, principalmente, compreender o espaço no qual está inserido, observando os aspectos físicos e sociais. Além disso, diante da diversidade de recursos tecnológicos hoje disponíveis, possibilita a elaboração de trabalhos que outrora demandariam tempo muito maior. Nisso enxerga-se a potencialidade de uma certa aceleração no ato de adquirir o conhecimento geográfico do ambiente.

O mapeamento pedológico, sobretudo em escala de detalhe, entra nesse contexto, uma vez que indubitavelmente necessita, para sua elaboração, da união entre as etapas de campo e gabinete e, é favorecida por uma série de aparatos tecnológicos que permitem em tempo, mais ou menos curto sua execução.

Nesse sentido, o presente trabalho apresenta a aplicação dessas etapas de trabalho na formação do geógrafo em uma das áreas de grande importância para esse profissional: a pedologia e o entendimento das relações solo-relevo. O produto das etapas estruturadas da pesquisa redundou na elaboração de um mapeamento pedológico em escala de detalhe em uma porção do município de Morungaba-SP.

\section{Mapeamento pedológico no contexto de uma disciplina da graduação}


A preocupação com o conhecimento dos solos acha se registrado desde as antigas civilizações que sentiam a necessidade em conhecer as melhores terras para a produção agrícola. Os estudos pedológicos iniciam-se com as pesquisas realizadas na Rússia por Dokuchaiev em 1880, que inicialmente buscava explicar a formação do solo e estabelecer um sistema de classificação. No contexto brasileiro, ainda no início do século XX surgem os primeiros estudos de classificação de solo, tendo seu apogeu a partir dos levantamentos realizados pelo projeto RADAM BRASIL na década de 1970. Vale ressaltar, nesse sentido, a sistematização do Sistema Brasileiro de Classificação de Solos (SBCS, 2006), com a contribuição de pesquisadores de todo o território nacional sob a égide da Empresa Brasileira de Pesquisa Agropecuária (EMBRAPA).

No ano de 2016 foi estabelecido o Programa Nacional de Solos do Brasil - PRONASSOLOS (POLIDORO et al, 2016), que visa preencher uma lacuna no reconhecimento do território brasileiro: o reconhecimento multiescalar em mapeamentos pedológicos. O desenvolvimento desse programa demonstra que, claramente há a necessidade de um melhor reconhecimento contemporâneo dos solos, em escalas adequadas e fazendo uso de atividades de campo e mapeamentos em laboratório. Com isso, notase uma evolução nos estudos pedológicos, contribuindo efetivamente com a expansão do conhecimento Geográfico.

A pedologia, que tem como estudo os processos relativos à origem e formação de solos, estabelece grande importância na Geografia, pois, sendo o solo "um material que evolui no tempo, sob a ação dos fatores naturais ativos na superfície terrestre" (MUGGLER, et al., 2005, p. 66), torna-se um indicativo de uma série de fenômenos ocorridos na paisagem.

O geógrafo traz nas suas atribuições a responsabilidade por uma abordagem holística e integrada do conhecimento, deste modo algumas disciplinas são indissociáveis, devendo ser trabalhadas em conjunto em sua formação, de modo que, é imprescindível uma base sólida de disciplinas que the são alicerce. Sob esse ponto de vista é salutar a busca por trabalhos que envolvam técnicas, métodos e procedimentos de diferentes especialidades da ciência geográfica.

$\mathrm{O}$ relato de experiência aqui apresentado parte dessa premissa, ao passo que apresenta o produto de integração entre algumas especialidades geográficas, sob o pressuposto do mapeamento pedológico. Para além do mapeamento em si, o que se depreende é que no percurso para sua efetivação, diversas disciplinas estiveram envolvidas, tais como: Pedologia e Geomorfologia, Geoprocessamento e Cartografia Temática.

Não obstante, cada uma com sua especificidade contribuíram de maneira que fosse possível a realização do referido mapeamento. 


\section{Caracterização da área de estudo}

Morungaba é um município que pertence à Região Metropolitana de Campinas, conforme o mapa 1, emancipado de Itatiba em fevereiro de 1964, possui uma população de aproximadamente 12.952 mil habitantes, (SEADE 2010), em uma extensão territorial de 146,5 $\mathrm{km}^{2}$. O município faz divisa com a Macrozona1, que corresponde a uma área de $222.786 \mathrm{~km}^{2}$, cerca de $27 \%$ da área do município de Campinas, área de preservação ambiental que se limita também com os municípios, Jaguariúna, Pedreira e Valinhos, compreende os Distritos de Sousas e Joaquim Egídio.

Segundo a classificação de Koppen, o clima do município de Morungaba é classificado como Cwb, (clima mesotérmico com verões amenos e estação seca de inverno), ou seja, o mês mais frio apresenta média mensal inferior à $17 \mathrm{o} \mathrm{C}$ e, no verão, o mês mais quente tem média que tende a não ultrapassar à 22o C; no mês mais seco recebe menos de $40 \mathrm{~mm}$ de chuva. O clima do município é fortemente influenciado por várias massas de ar: Equatorial Continental (Ec), Massa Tropical Atlântica (Ta) e a Massa Polar Atlântica (Pa) (CÂMARA MUNICIPAL DE MORUNGABA, 2006).

$\mathrm{Na}$ área de estudo, a vegetação apresenta algumas espécies isoladas da Mata Atlântica, árvores esparsas, com predominância de braquiárias (Figura 2), caracterizando uma área de pasto, mas com a existência de plantação recente de eucaliptos, como mostra a Figura 3.

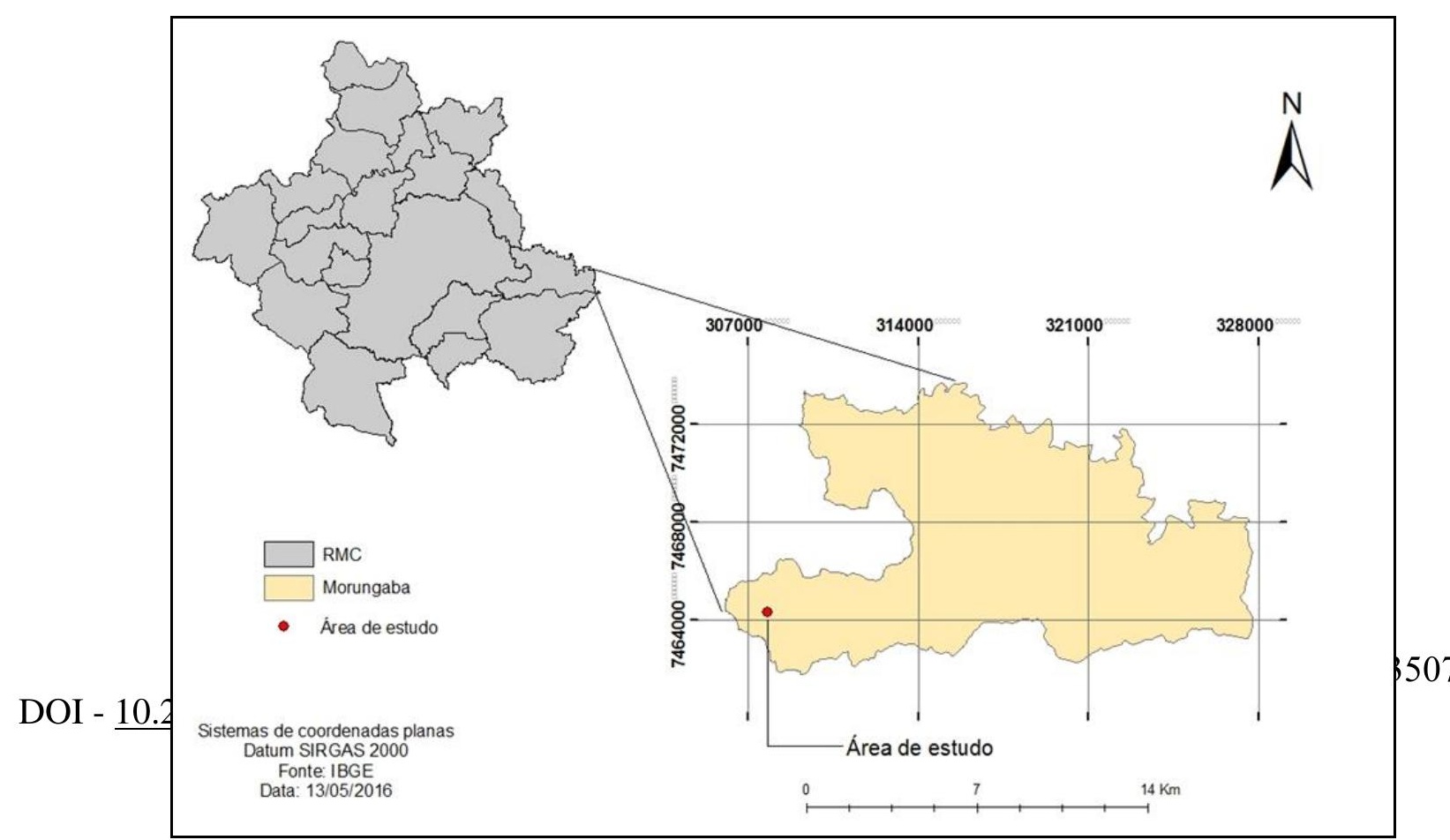


Figura 1. Mapa de localização de Morungaba na RMC e localização da área de estudo.

Fonte: IBGE. Elaborado pelos autores

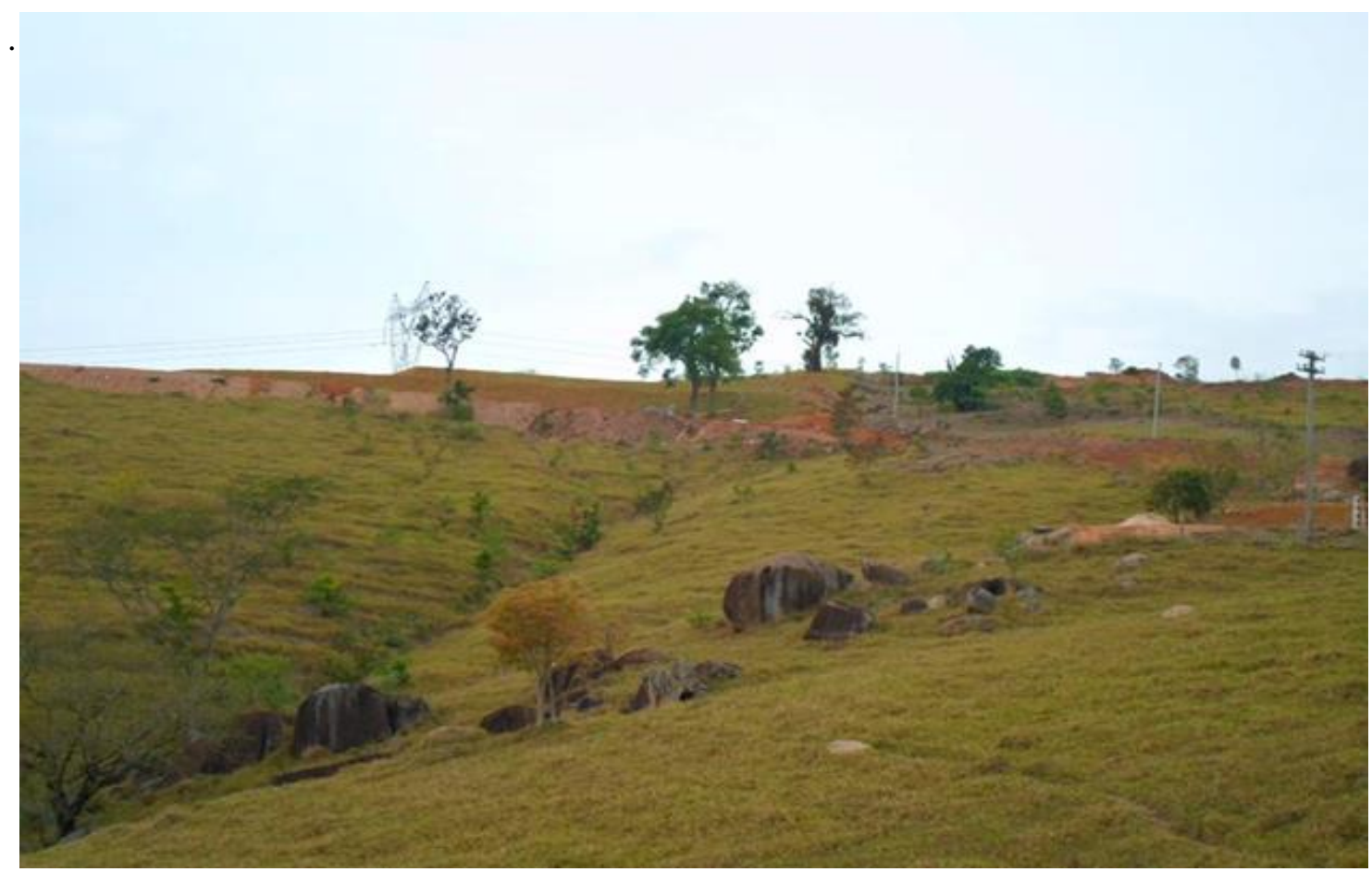

Figura 2.Vegetação predominante da área de estudo. 

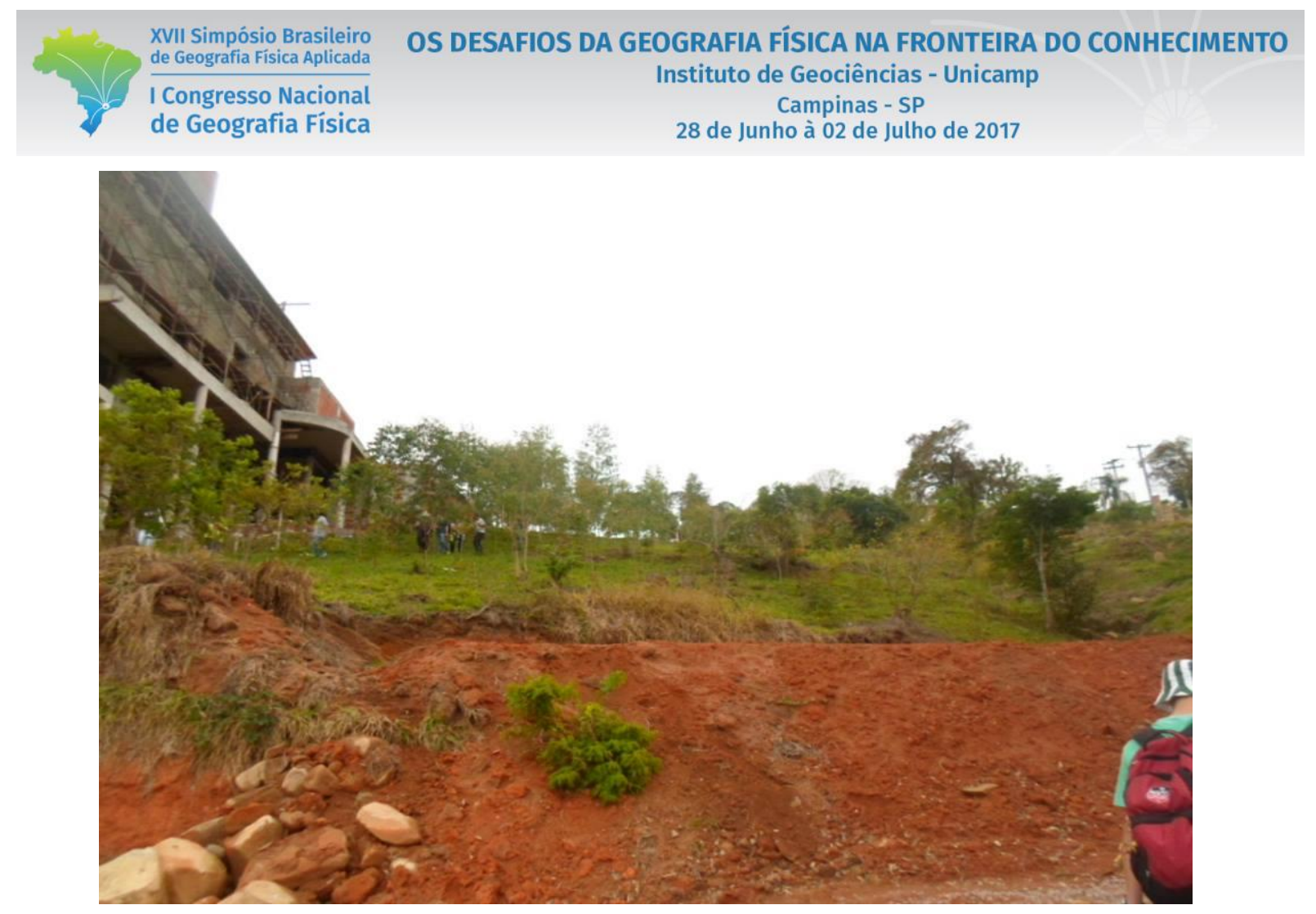

Figura 3. Plantação de Eucalipto

O lote do condomínio conta com a presença de matacões, que são blocos de rochas subterrâneos ou superficialmente expostos, moldados pela ação intempérica da água da chuva, dos ventos e pela variação da temperatura, que lhe dará uma aparência geralmente arredondada. É de suma importancia conhecer a geomorfologia da região, que acordo o mapa de Unidades Geomorfológicas de Ross e Moroz, (1997), pertence à Província Geomorfológica do Planalto Atlântico, composto em sua maioria por morros altos e alongados e colinas de topos convexos, que variam entre $700 \mathrm{~m}$ a $1200 \mathrm{~m}$ de altimetria, com 20 a $30 \%$ de declividade, apresentando formação litológica predominantemente de granitos e gnaísses.

O Mapa pedológico do Estado de São Paulo apresenta uma variedade na taxonomia de solos, sendo os mais expressivos os Argissolos, no Planalto Ocidental e também nas proximidades da área de estudo, os Latossolos na Depressão Periférica Paulista, bem como, na região das Cuestas e os Cambissolos, no Planalto Atlântico. É importante salientar que os mapeamentos pedológicos já feitos, em sua maioria, se apresentam em pequenas escalas, tornando o nível de detalhamento muito pequeno, o que inviabiliza a caracterização pedológica de uma área como a que é objeto desse estudo.

Além do solo, outros aspectos da paisagem da região foram analisados cartograficamente. Através dos conhecimentos adquiridos ao longo do curso, bem como com o trabalho de gabinete voltado ao uso da técnica, foi possível a elaboração de um mapa hipsométrico e um mapa de declividade, já que a cartografia é uma linguagem peculiar da Geografia e que potencializa a compreensão espacial. 


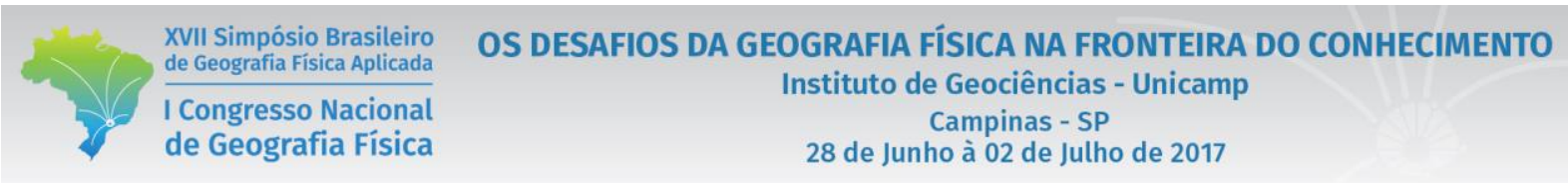

No que se refere à altimetria da área de estudo, (figura 4), observa-se que o lote se encontra na classe de $18 \%$ e $21 \%$ de declividade, apresentando um valor médio. A partir do mapa hipsométrico, percebe-se que a área em questão está também próxima a uma região de altimetria que não excede a $711 \mathrm{~m}$, configurandose como uma área de baixa declividade que banha a parte sul da área de estudo.

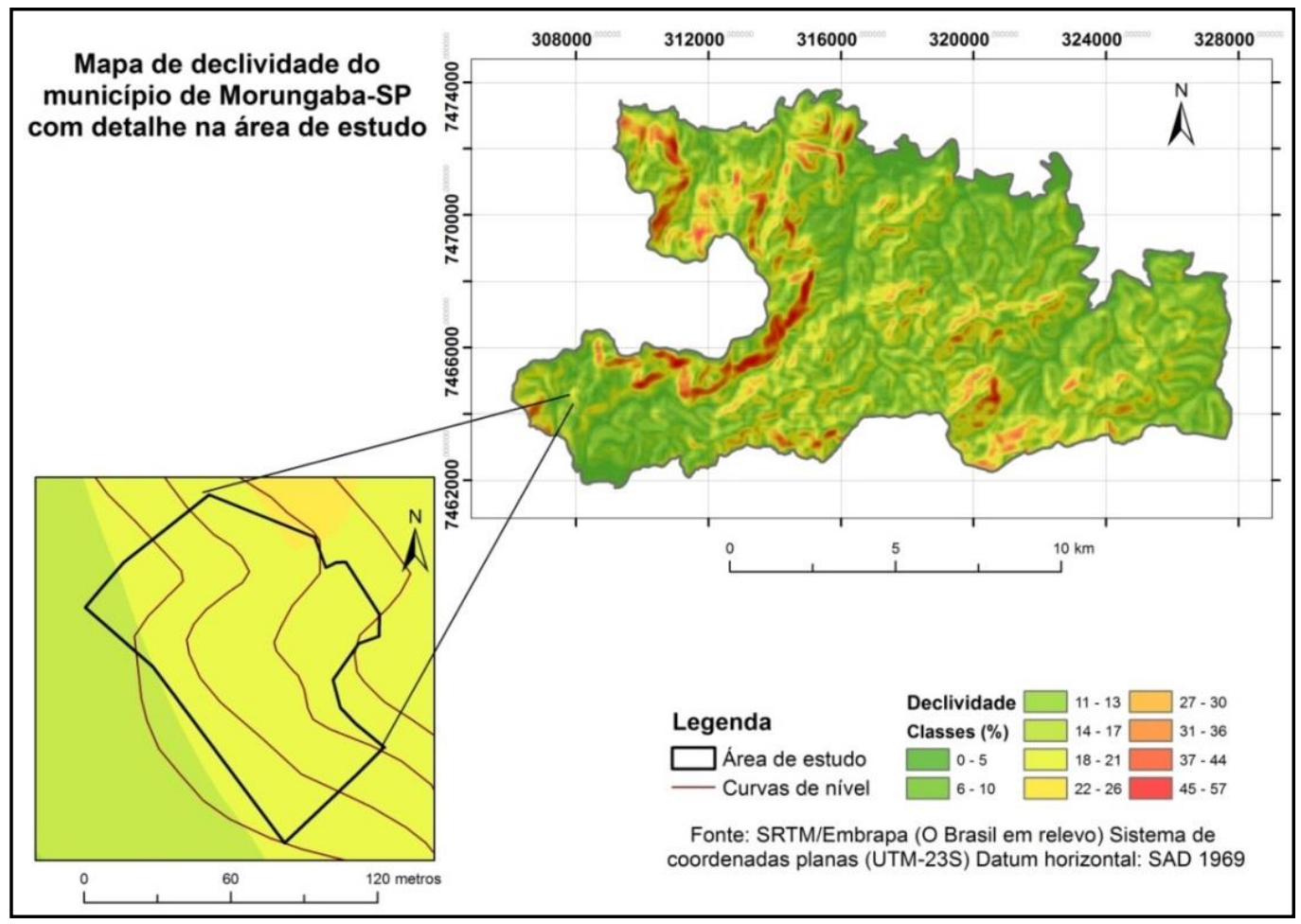

Figura 4. Mapa de Declividade do Município de Morungaba-SP com detalhe na área de estudo. Elaborado pelos autores 


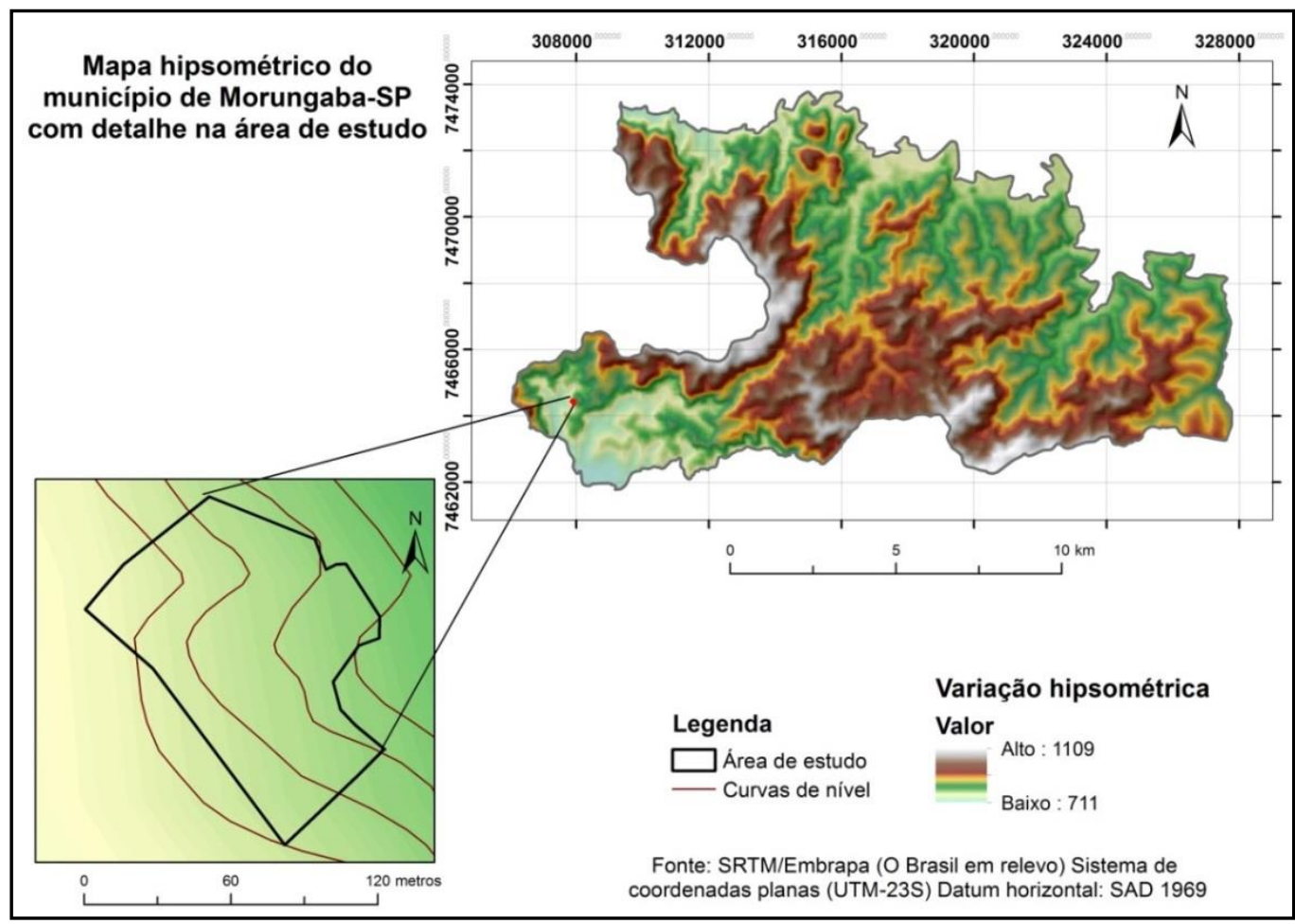

Figura5. Mapa hipsométrico do município de Morungaba-SP com detalhe na área de estudo.

Elaborado pelos autores

O município de Morungaba em sua borda oeste, divisa com o município de Campinas e também próxima ao lote, possui declividades bastante acentuadas, variando entre 45 a $57 \%$, e sabe-se que, quanto mais inclinada uma vertente, maiores são os riscos de processos erosivos. Neste sentido é importante ressaltar que os solos dessa região estão suscetíveis ao processo de erosão, sujeito a perda pelas forças ativas da chuva, uma vez que a declividade atua na capacidade de escoda e absorção da água.

Essas informações são imprescindíveis para a análise do solo, pois o relevo é um fator que na maioria das vezes é preponderante na classificação pedológica.

\section{Materiais, métodos e procedimentos}

O estudo realizado utilizou-se de leituras minuciosas sobre a pedogênese, fatores de formação do solo, bem como, de manuais de descrição morfológica. Acerca disso, a classificação dos solos no lote do Condomínio Córrego dos Cambarás, foi realizada, com a apresentação de dados obtidos principalmente 
através do trabalho de campo. Essa metodologia é a mais utilizada quando se trata da obtenção de dados quantitativos. O mapa pedológico da área envolvida foi desenvolvido a partir das coletas de amostras de solo, descrevendo sua morfologia, bem como algumas de suas propriedades químicas.

As coletas foram feitas com a realização de tradagens, que é a retirada de solo em profundidade, onde geralmente são feitas em lugares em que não há cortes de estrada que permitam a visualização do perfil do solo. O equipamento utilizado foi o trado holandês, que torna a operação mais fácil e rápida, além de permitir a retirada da amostra na profundidade correta e da mesma quantidade de solo de todos os pontos amostrados. Depois de ser escolhido o local da perfuração, foi removida a vegetação rasteira ou o excesso de galhos secos, depositados na superfície, para que a atividade fosse iniciada. $\mathrm{O}$ trado tem capacidade de coletar $20 \mathrm{~cm}$ de solo por vez, a primeira coleta de 0 a $10 \mathrm{~cm}$ e a segunda de 10 a $20 \mathrm{~cm}$ e assim sucessivamente. A profundidade pode variar entre centímetros ou metros, em alguns pontos a tradagem é interrompida pelos materiais rolados, blocos ou pedregulhos, mas para que as características da área sejam bem representadas pelos pontos de coleta é fundamental que seja coletada amostras, até que se chegue próximo à rocha-mãe.

O armazenamento foi feito com a utilização de pedocomparadores ${ }^{1}$ para posteriores análises no que diz respeito às propriedades físicas como cor e textura. A cor do solo foi facilmente perceptível e determinável, analisada sob luz solar do período entre $9 \mathrm{~h}$ e $15 \mathrm{~h}$ com a comparação da cor da amostra com as cores existentes na Carta Munsell. A textura, responsável pela quantidade de água retida no solo, foi avaliada através do tato, depois de umedecido e esfregado entre os dedos. De acordo com Lemos e Santos (1984), a areia dá sensação de atrito, o silte, de sedosidade e a argila, de plasticidade e pagajosidade. A consistência também é uma categoria de análise, feita no campo, onde é possível identificar a dureza ou tenacidade do solo, pressionando-o entre o dedo polegar e o indicador.

Com o uso do aparelho de posicionamento global (GPS), foram marcados todos os pontos nos locais de perfuração, para que posteriormente com a utilização das ferramentas do ARCGIS, fosse possível fazer o levantamento dos dados a fim de se produzir o mapa pedológico da área de estudo.

\section{Resultados e Discussões}

Com as tradagens realizadas em campo, somadas às análises de perfis topográficos, e análises de amostras em laboratório, e também o com auxílio do SBCS (2006), foi identificado uma possível presença de CAMBISSOLO HÁPLICO Tb Eutrófico latossólico, (Figura 6), sem a devida confirmação pela falta da análise dos micronutrientes. Deste modo, pode-se ressaltar novamente a importância do mapeamento de

\footnotetext{
${ }^{1}$ São caixas de madeira retangulares de aproximadamente $50 \mathrm{~cm}$, de forma que em cada uma dessas caixas possam armazenadas 100 amostras.
} 


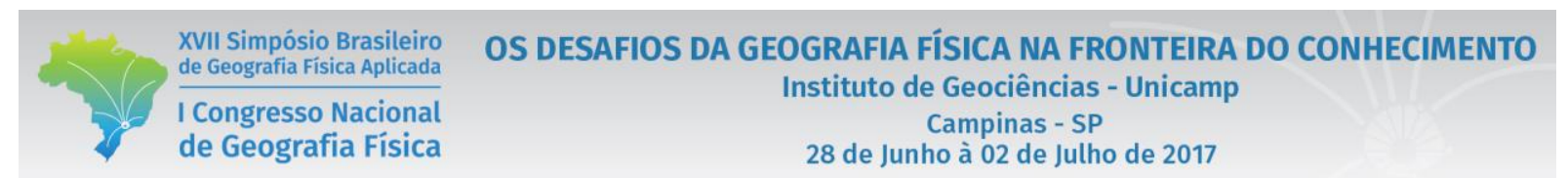

detalhe, que nos possibilita a identificar e classificar com precisão as diferentes taxonomias, tendo emvista que o Mapa Pedológico do estado de São Paulo classifica os solos da área de estudo, como Argissolos e Cambissolos, cuja ocorrência está intimamente ligada à topografia da região e ao material de origem. A profundidade dos solos é variável, mas em geral são pouco profundos e profundos, IAC, (s/d).

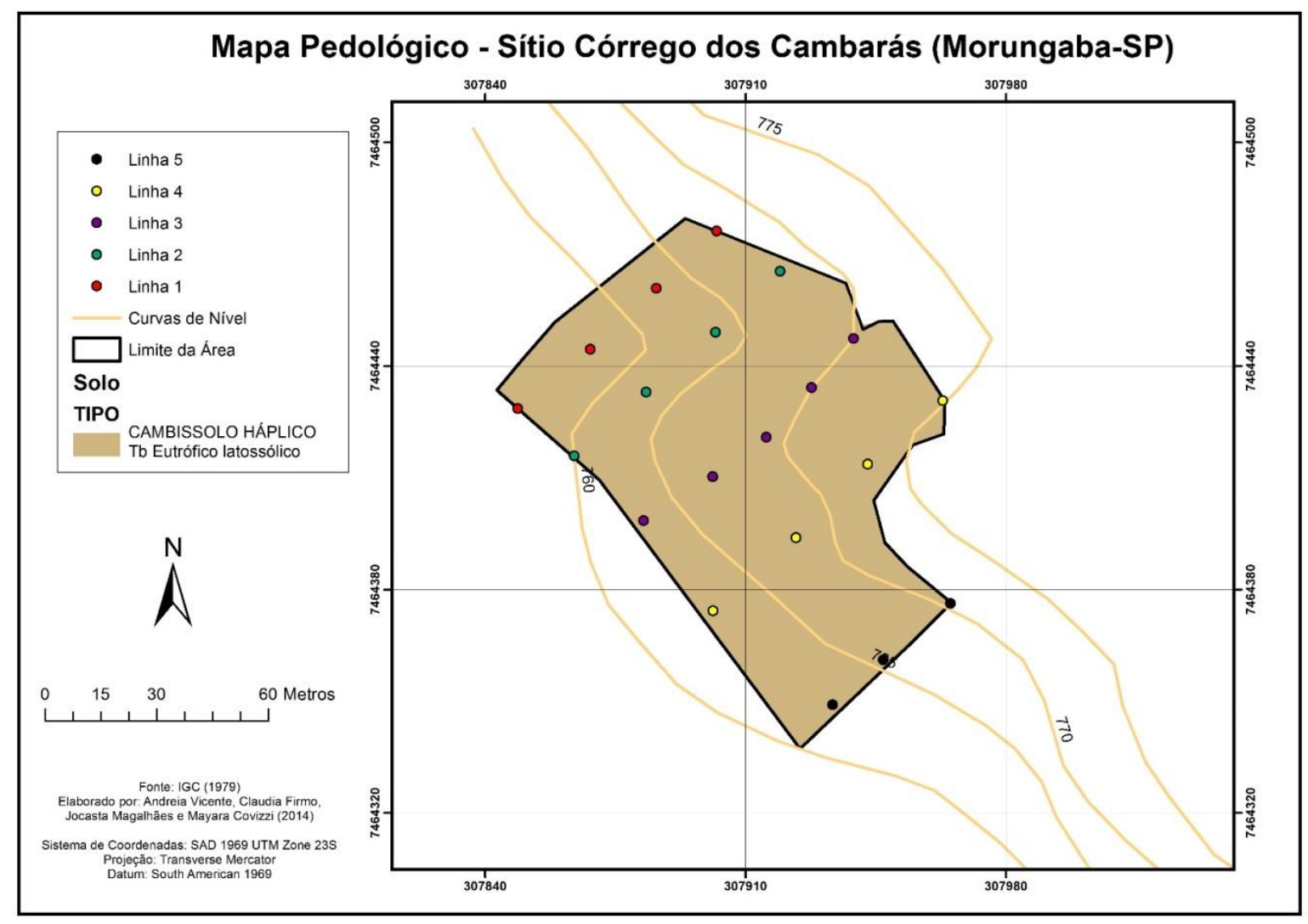

Figura 6. Mapa Pedológico do lote no Condomínio Córrego dos Cambarás, Morungaba-SP

Elaborado pelos autores

O solo analisado está em relevo ondulado, com baixas restrições ao uso agrícola no que diz respeito à disponibilidade de nutrientes, como o cálcio, magnésio, potássio e fósforo, além de uma deficiência na disponibilidade de alumínio, o que favorece o desenvolvimento das plantas, porém, possuem elevada erodibilidade, forte risco de degradação e forte presença de pedregosidade e afloramentos de rochas.

A partir do exposto, pode-se conferir a importância do trabalho de campo e de gabinete no contexto da graduação para o mapeamento pedológico, que consiste num exercício importante, para um bom aproveitamento do solo, para o planejamento e diagnóstico ambiental e gestão territorial, que são atividades atribuídas ao Geógrafo no mercado de trabalho. Os estudos pedológicos atuam também como 


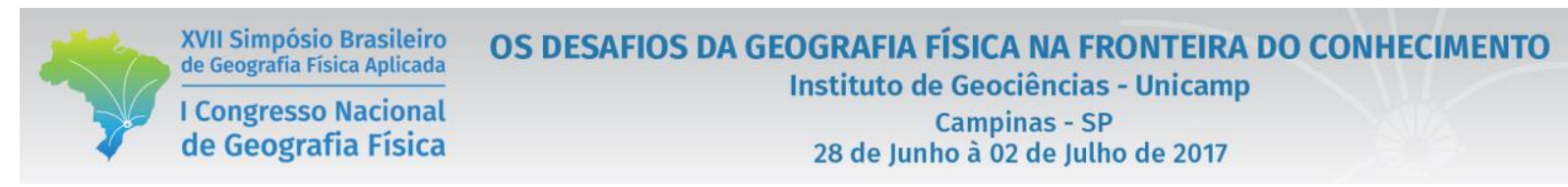

fontes básicas de pesquisas e estudos sobre agricultura e geotecnia. Tal experiência contribuiu para 0 aprimoramento dos conhecimentos adquiridos em sala, bem como para o treinamento da nossa profissão. Incentiva-se desse modo a ampliação de trabalhos dessa alcunha, no sentido da busca da melhoria continuada da formação das próximas gerações de geógrafos.

\section{REFERÊNCIAS}

\section{CAMARA MUNICIPAL DE MORUNGABA. Disponível em:}

http://morungaba.sp.gov.br/Content/Legislacao/Lei_organica_Morungaba_mai_2008.pdf acesso: 18 de junho de 2016

CAMPOS, R. R.; PLÁCIDO, V. L. S. O trabalho de campo como uma proposta de ensino de Geografia. Revista Geográfica de América Central, Costa Rica, p. 1-21, II semestre 2011.

CANTÃO, C.M. Programa - Tipo de excursões geográficas para fins didáticos. Boletim Geográfico/IBGE, Rio de Janeiro, $\mathrm{n}^{\circ}$ 134, p. 503, 1956.

EMBRAPA, Empresa Brasileira de Pesquisa Agropecuária. SISTEMA BRASILEIRO DE CLASSIFICAÇÃO DE SOLO. $2^{\mathrm{a}}$ edição: Brasília-DF. 2006.

FUNDAÇÃO SEADE, 2010. Disponível em: <http://www.seade.gov.br/banco-de-dados/>. Acesso em 20 de setembro de 2015.

GUIMARÃES, E. M. A. Trabalhos de campo em bacias hidrográficas: os caminhos de uma experiência em educação ambiental. Campinas: Unicamp. 1999. 172 p. Dissertação de mestrado - Pós-Graduação em Geociências, Depto. De Geociências aplicadas ao ensino, Unicamp, Campinas, 1999.

Instituto Agronômico de Campinas (IAC). Cambissolos. S/d, acesso ao link: http://www.iac.sp.gov.br/solossp/pdf/Cambissolos.pdf. Acessado em, 20 de fevereiro de 2016.

LEMOS, R. C.; SANTOS, R. D. Manual de Descrição e Coleta de Solo no Campo 1984.

MUGGLER, C. C.; CARDOSO, I. M.; REZENDE, M.; FONTES, M. P. F.; ABRAHÃO, W. A. P.; CARVALHO, A. F.; Conteúdos básicos de Geologia e Pedologia para as disciplinas de Sol 213, sol 215 e sol 220.

ROSS, J. L. S. MOROZ, I. C. Mapa Geomorfológico do Estado de São Paulo, 1997.

POLIDORO, J. C.; MENDONÇA-SANTOS, M. de L.; LUMBRERAS, J. F.; COELHO, M. R.; CARVALHO FILHO, A. de; MOTTA, P. E. F. da; CARVALHO JUNIOR, W. de; ARAUJO FILHO, J. C. de; CURCIO, G. R.; CORREIA, J. R.; MARTINS, E. de S.; SPERA, S. T.; OLIVEIRA, S. R. de M.; BOLFE, E. L.; MANZATTO, C. V.; TOSTO, S. G.; VENTURIERI, A.; SA, I. B.; OLIVEIRA, V. A. de; SHINZATO, E.; ANJOS, L. H. C. dos; VALLADARES, G. S.; RIBEIRO, J. L.; MEDEIROS, P. S. C. de; MOREIRA, F. M. de S.; SILVA, L. S. L.; SEQUINATTO, L.; AGLIO, M. L. D.; DART, R. de O. Programa Nacional de Solos do Brasil (PronaSolos). EMBRAPA. Rio de Janeiro, 2016 54p.

VENTURI, L. A. B. O papel da técnica no processo de Produção Científica. In: VENTURI, L. A. B. (Org). Praticando Geografia: técnicas de campo e laboratório. São Paulo: Oficina de Textos, 2005. 